\title{
DigitAL INNOVATION MANAGEMENT: REINVENTING INNOVATION MANAGEMENT RESEARCH IN A DIGITAL WORLD
}

\author{
Satish Nambisan \\ Lubar School of Business, University of Wisconsin-Milwaukee, 3202 N. Maryland Avenue, \\ Milwaukee, WI 53211 U.S.A. \{nambisan@uwm.edu\} \\ Kalle Lyytinen \\ Weatherhead School of Management, Case Western Reserve University, 10900 Euclid Avenue, \\ Cleveland, OH 44106 U.S.A. \{kj113@case.edu\} \\ Ann Majchrzak \\ Marshall School of Business, University of Southern California, \\ Los Angeles, CA 90089 U.S.A. \{majchrza@usc.edu\} \\ Michael Song \\ School of Economics and Management, Xi'an Technological University, WeiYang District, \\ Xi'an City CHINA \{drmichaelsong@163.com\}
}

\begin{abstract}
Rapid and pervasive digitization of innovation processes and outcomes has upended extant theories on innovation management by calling into question fundamental assumptions about the definitional boundaries for innovation, agency for innovation, and the relationship between innovation processes and outcomes. There is a critical need for novel theorizing on digital innovation management that does not rely on such assumptions and draws on the rich and rapidly emerging research on digital technologies. We offer suggestions for such theorizing in the form of four new theorizing logics, or elements, that are likely to be valuable in constructing more accurate explanations of innovation processes and outcomes in an increasingly digital world. These logics can open new avenues for researchers to contribute to this important area. Our suggestions in this paper, coupled with the six research notes included in the special issue on digital innovation management, seek to offer a broader foundation for reinventing innovation management research in a digital world.
\end{abstract}

Keywords: Digitizing, digitization, innovation, theory, management

\section{Introduction}

Digital innovation is the use of digital technology during the process of innovating. Digital innovation can also be used to describe, fully or partly, the outcome of innovation. Digital innovation has radically changed the nature and structure of new products and services, spawned novel value creation and value appropriation pathways, enabled innovation collectives that involve dynamic sets of actors with diverse goals and capabilities, produced a new breed of innovation processes, and, more broadly, transformed entire industries in its wake (e.g., Boudreau and Lakhani 2013; Hui 2014; Iansiti and Lakhani 2014; OECD 2016; Porter and Heppelmann 2014, 2015).

The rise of digitization has led scholars to increasingly question the explanatory power and usefulness of extant innovation theory and related organizational scholarship (Barrett et 
al. 2015; Benner and Tushman 2015; Goldfarb and Tucker 2012; Greenstein et al. 2013; Yoo et al. 2012). For example, Benner and Tushman (2015) recently noted that

because of the shift in the locus of innovation and because some of our core organizing axioms may be challenged or fundamentally changed by the digital revolution, the nature of innovation and organizational scholarship may be at a transition point (p. 2).

This transition from innovation to digital innovation comes as a golden opportunity to be seized upon by information systems (IS) researchers. IS researchers have, for the last four decades, been at the forefront in observing the dawn and consecutive wakes of digitization in organizations and, broadly, in society, and explaining its repercussions. By and large, their efforts were originally focused on effects of digitizing internal organizational processes (e.g., Fichman 2004; Swanson 1994). More recently, there has been an expansion to identifying and articulating unique aspects of digitization in industries, specific organizational domains, or product families (e.g., Agrawal et al. 2013; Anderson and Agarwal 2011; Greenstein et al. 2013; Xue et al. 2013). They have especially highlighted the paradoxes and dilemmas that digitization creates for organizations developing, deploying, and managing digital innovation (e.g., Breshnahan and Greenstein 2014; Kallinikos et al. 2013; Lyytinen et al. 2016; Nambisan 2013; Tilson et al. 2010; Tiwana et al. 2010; Yoo et al. 2010). IS scholars have also been increasingly focused on the materiality of digitization within innovation processes and outcomes (e.g., Boland et al. 2007; Lee and Berente 2012; Majchrzak et al. 2013).

As a consequence of this growing research on digitization, we suggest that it is time to develop theories that explicitly incorporate the variability, materiality, emergence, and richness of the sociotechnical phenomenon called digital innovation. The time for new theorizing about digital innovation is, therefore, now and it is this challenge that motivated our choice of proposing and organizing this special issue.

To pursue the call for more encompassing theories of digital innovation, we adopt a conceptualization of digital innovation that is meant to be inclusive and inviting of perspectives and disciplines that may not have contributed in the past to research on innovation management. We conceptualize digital innovation as the creation of (and consequent change in) market offerings, business processes, or models that result from the use of digital technology. Stated differently, in digital innovation, digital technologies and associated digitizing processes form an innate part of the new idea and/or its development, diffusion, or assimilation. Given the above conceptualization, digital innovation management refers to the practices, processes, and principles that underlie the effective orchestration of digital innovation.

Our definition of digital innovation is intended to capture three important and concurrent phenomena. First, our definition of digital innovation includes a range of innovation outcomes, such as new products, platforms, and services as well as new customer experiences and other value pathways; as long as these outcomes are made possible through the use of digital technologies and digitized processes, the outcomes themselves do not need to be digital. Second, our definition of digital innovation includes a broad swath of digital tools and infrastructure (e.g., 3D printing, data analytics, mobile computing, etc.) for making innovation possible. Third, our definition includes the possibility that the outcomes may be diffused, assimilated, or adapted to specific use contexts such as typically experienced with digital platforms. Our broad definition bridges a research focus on intra-organizational innovation management (e.g., Swanson 1994) with research on digital products, platforms, ecosystems, and infrastructure (Bharadwaj et al. 2013; Tilson et al. 2010; Tiwana et al. 2010; Yoo et al. 2012; Yoo et al. 2010).

In what follows, we first summarize the existing research challenging key assumptions that underlie extant theories informing innovation management. Then, using these challenges to assumptions as our jumping off point, we formulate several suggestions to move digital innovation management theory forward. This discussion, along with the six research notes that make up the special issue, offer a broader foundation to theorize and reflect upon the implications of digital technology for innovation management.

\section{Challenging Key Assumptions of Innovation Management Theories}

Received theories in innovation management have primarily focused on addressing three basic questions.

- How do innovations form/evolve?

- How should actors/entities organize for innovation?

- How does the nature of innovation and the organization of innovation interact?

Underlying these questions (and their related theories) are three key assumptions.

(1) Innovation is a well-bounded phenomenon focused on fixed products and therefore the question of how innovations form/evolve is a well-bounded question. 
(2) The nature of the innovation agency is centralized, and therefore actors/entities can organize for innovation.

(3) Innovation processes and outcomes are distinctly different phenomenon, and therefore there is interaction between the nature and organization of innovation that can be explicitly theorized.

With the digitization of innovation, these assumptions are increasingly being challenged (e.g., Henfridsson et al. 2014; Nylén and Holmström 2015; Yoo et al. 2012), raising the need for new theory development and inviting alternative conceptualizations. Below we briefly review the research challenging these assumptions, paving the path for new theory development.

\section{Is Innovation a Well-Bounded Phenomenon?}

Prior studies on innovation management, have, by and large, presupposed a fixed, discrete set of boundaries and features for the new product (or service) idea that underlies a market opportunity (e.g., Ulrich and Eppinger 2011). The continued popularity of product development methodologies such as stage gate testifies to this (e.g., Grönlund et al. 2010). Unique characteristics of digital artifacts - they are malleable, editable, open, transferable, etc. (Yoo et al. 2010; Zittrain 2008) — dress them with "ambivalent ontologies” (Kallinikos et al. 2013). The scope, features and value of digital offerings can continue to evolve even after the innovation has been launched or implemented. Most digital designs remain somewhat incomplete and in a state of flux where both the scale and scope of the innovation can be expanded by various participating innovation actors (Hanseth and Lyytinen 2010; Lyytinen et al. 2016). Thus, this imparts an unprecedented level of unpredictability and dynamism with regard to assumed structural or organizational boundaries of the digital innovation, be it a product, platform, or service. Therefore, boundaries on what is or is not an innovation outcome have become more porous and fluid.

Innovation processes, in addition to outcomes, also have become less bounded, in terms of their temporal structure. Specifically, the digitization of innovation processes helps to break down the boundaries between different innovation phases and brings a greater level of unpredictability and overlap in their time horizons. For example, new digital infrastructures (e.g., 3D printing, digital makerspaces, etc.) enable product ideas to be quickly formed, enacted, modified, and reenacted through repeated cycles of experimentation and implementation (Ries 2011), making it less clear as to when a particular innovation process phase starts and/or ends. Similarly, digital infrastructures (e.g., cloud computing) facilitate rapid scaling up (or down) of product implementation plans. These create a new level of fluidity in innovation processes, allowing them to unfold in a nonlinear fashion across time and space.

Further, less bounded innovation outcomes and processes also reflect newer success criteria (for example, ones that reflect the potential for radical rescoping of the product, communitybased generativity, platform-based network effects, etc.) and demand newer theories that incorporate such metrics and underlying factors.

\section{Can Innovation Agency Be Predefined?}

With digital innovation, there is a shift toward less predefined and more distributed innovation agency, particularly in technology intensive industries; this shift has been referred to as distributed innovation (e.g., Lakhani and Panetta 2007; Sawhney and Prandelli 2000), open innovation (Chesbrough 2003), and network-centric innovation (Nambisan and Sawhney 2007) among others. By distributed innovation agency, we mean an innovation context wherein a dynamic and often unexpected collection of actors with diverse goals and motives-often outside the control of the primary innovator - engage in the innovation process (e.g., Bogers and West 2012). This heterogeneous constellation of actors as a whole often constitutes the agency necessary to innovate successfully. Importantly, such collectives are also highly dynamic in that actors (individuals, organizations, etc.) can opt in and out while their goals change, new competencies are needed, motivations shifts, complementary capabilities need to be garnered, new constraints and opportunities emerge, or varying contributions become recognized (Lusch and Nambisan 2015).

This shift has been largely made possible by digital technologies infused into innovation outcomes and processes. For innovation outcomes, digital platforms and open standards enable collectives (of organizations or individuals) to pursue innovation collaboratively (e.g., Boudreau 2010; Bresnahan and Greenstein 2014; Gawer and Cusumano 2014; Parker et al. 2016; Tiwana et al. 2010). For innovation processes, collaboration among collectives is enabled by such digital infrastructural capabilities as knowledge sharing and work execution platforms (e.g., GitHub), crowdsourcing (e.g., Top Coder), crowdfunding (e.g., Kickstarter), virtual worlds (e.g., Second Life), digital makerspaces, and dedicated social media (e.g., OpenStack). The scope, functionality, and other characteristics of these enabling digital technologies fundamentally shape the scope, content, and direction of the distributed innovation agency (e.g., Chandra and Leenders 2012; Majchrzak and Malhotra 2013; Smith et al. 2013). This highlights the growing significance of incorporating the features of digital 
technology into theories about innovation management that make distributed agency possible.

Specifically, this shift creates the need for innovation management theories to address two questions:

- How does a firm organize for innovation when its partners and their contributions are diverse, unknown or ill defined?

- How do innovation collectives form, evolve, and contribute to a shared innovation agenda?

More broadly, the digitization of the processes and platforms that facilitate distributed agency calls for new theories explaining how digital technologies enable, constrain or shape the nature of innovation as a collective action (e.g., Lyytinen et al. 2016; Yoo et al. 2012).

\section{Can Studies of Innovation Processes and Out- comes Focus on One and Not on the Other?}

Traditionally, innovation management studies have focused either on the process (with limited attention to the innovation outcome) or the innovation outcome (with limited attention to the innovation process) (e.g., Ahmad et al. 2013; Sivasubramaniam et al. 2012). While the extensive research on product modularity offers the "mirror hypothesis" - that a product's modular structure should be aligned with the product development organization-most complexities associated with the interdependence of outcome and process organization are ignored (e.g., Baldwin and Clark 2000; Danese and Filippini 2010; Langlois 2002; Sanchez and Mahoney 1996; Schilling 2000; Staudenmayer et al. 2005).

The complexities, however, cannot be ignored. With digitization, dependencies between innovation processes and innovation outcomes are complex and dynamic. Boland et al. (2007), for example, demonstrated that in innovating construction projects, the use of $3 \mathrm{D}$ tools as a digital process infrastructure led to unexpected interactions and collaborations between different trades, designers, and other stakeholders, generating multiple "wakes of innovation." Similarly, Dougherty and Dunne (2012) demonstrated that the use of digital technologies during new drug discoveries led to the reorganization of the innovation focus and created a new set of activities necessary among groups of scientists, which, in turn, held implications for innovation outcomes. These documented effects were all unintended. Indeed, as these and other recent studies suggest (e.g., Bailey et al. 2012; Lee and Berente 2012), digitizing innovation involves processes and outcomes (product/services) shaping and being shaped by the other.
Clearly, the research community faces new questions. For example, how does the use of digitally enabled infrastructures constrain or enable digital designs and participation in innovation? How do digital designs shape the use of digitally enabled infrastructure? New theories are needed that take into consideration the endogeneity associated with both outcomes and processes that are inherent in digital innovation. Such theories can build on the extant product/organizational modularity literature but need to consider digital technologies (and their characteristics) not as a mere context but as an active innovation ingredient that influences the nature of modularity (e.g., Henfridsson et al. 2014).

\section{New Logics of Theorizing about Digitization of Innovation: A Research Agenda}

Our discussion so far highlights the need to revisit the three pivotal assumptions regarding innovation management: definition of innovation as having clearly delimitable boundaries, innovation agency as being centralized and predictable, and innovation outcomes as occurring independently of process and visa versa. In challenging these assumptions, there is an opportunity for new theory building. To start on this new theorizing, we offer four theoretical logics or conceptual elements that IS researchers are particularly skilled at exploring. In formulating each of the four theoretical logics, we also raise a set of new research questions. Table 1 summarizes our arguments.

\section{Dynamic Problem-Solution Design Pairing}

Given the unbounded nature of digital innovation, we suggest a shift from a focus on innovation processes and outcomes to a focus on dynamic problem-solution design pairing (von Hippel and von Krogh 2016). In particular, we suggest that the study of digital innovation management be one analyzed as a sporadic, parallel, and heterogeneous generation, forking, merging, termination, and refinement of problemsolution design pairs.

Innovation problems are primarily associated with unidentified and latent needs of users, customers or other stakeholders, while solutions refer here to digitized artifacts - their features, functionalities, and user affordances-and the surrounding sociotechnical contexts. By introducing the notion of problem-solution design pairs we highlight that digital innovation involves the continuous matching of the potential (or capabilities) of new and/or newly recombined digital technologies with original market offerings. Thus, digital in- 
Table 1. New Logics of Theorizing About Digitization of Innovation

Assumptions of Innovation
Management Theories that
Digital Innovation
Challenges

- Less bounded innovations: With digitization, (a) continuously shifting structural boundaries for innovation outcomes, and (b) continuously shifting spatial and temporal boundaries for innovation processes.

\section{- Less predefinition in} innovation agency: With digitization, a shift from predefined set of focal innovation agents to evolving, innovation collectives with diverse goals, motives, and capabilities.

- Less boundaries between innovation process and outcomes: With digitization, less demarcation and more complex, dynamic interaction between innovation processes and outcomes.
New Logics of Theorizing about Digitization of Innovation

Dynamic problem-solution design pairing: Digital innovation management as a sporadic, parallel, and heterogeneous generation, forking, merging, termination, and refinement of problem-solution design pairs.

Acknowledges the fluid boundaries of the innovation space and the potential for innovation agency to be distributed.

\section{Socio-cognitive sensemaking:}

Shared cognition and joint sensemaking as critical element of digital innovation management; "narratives" (embedded in digital artifacts and supported by digital technologies) as a vehicle for such socio-cognitive sensemaking.

Acknowledges the fluid boundaries of the innovation space and the heterogeneous actors that populate it (distributed innovation agency).

\section{Technology affordances and con-} straints: Considers digital technology use as sets of affordances and constraints for particular innovating actors and helps explain how and why the "same" technology can be repurposed by different actors or has different innovation outcomes in different contexts.

Acknowledges the receding distinctions (and the accompanying duality) between innovation processes and outcomes.

Orchestration: Problem-solution matching as a microfoundation of digital innovation orchestration; increasing role of digital technologies in enabling or supporting such orchestration.

Acknowledges the fluid boundaries of the innovation space and the potential for innovation agency to be distributed.
Questions Emerging from the New Theorizing Logics

- When, where, and under what conditions do digital innovation opportunities emerge? What theories can inform on the creation/discovery of such opportunities and the paths they take in their gradual evolution into products/ services?

- How are new digital capabilities and the problems/opportunities related to innovation paired? How do such pairings evolve and how much shifts and dynamics happen during the constant pairing of new solution potential and discovery of new types of problems?

- What theories and concepts could explain the temporal trajectories of digital innovation projects? What unique characteristics and aspects of digital technologies shape such trajectories? More broadly, what new theories may explain the dynamic nature of evolution of digital innovation?

- How should firms organize for the temporal "distensions" (in the innovation journey) facilitated by digital technologies? What new theories may explain firms' success in navigating the convergences and divergences in the formation and enactment of digital innovation opportunities?

- What are the tensions between digital and non-digital elements of an innovation and how do such tensions shape/ reshape the scope and functionalities of the offerings? How are such tensions resolved/managed and under what conditions?

- How do agents (actors) make sense and discover new meanings around digital technology and construct-related use scenarios and affordances? How do actors negotiate and adjust meanings around digital technology innovations and what makes them stabilize or break down?

- How do narratives serve as a vehicle for shared meaning-making in digital innovation? How do digital technologies support (and shape) the evolution of such narratives?

- How are analogous reasoning and metaphors deployed to discover new ways of generating digital innovations?

- What is the effect of distributed agency as a new potential and constraint (too many participants) in influencing socio-cognitive sensemaking around digital innovation? How does socio-cognitive inertia and related challenges of identity maintenance influence and/or curtail innovation?

- How do digital tools and infrastructure enable and constrain innovation outcomes? How do the nature and characteristics of digital innovation shape/ influence the use of digital tools and infrastructure?

- How are digital capabilities used in specific innovation contexts and across contexts as specific affordances? What generic new technology affordances are enabled by digital technologies and how do they influence innovation trajectories and outcomes? How do specific nonfunctional features of digital technology such as scale and speed of computation, differences in cost, geographic distribution, new forms of control, or new forms of analysis enable digital innovation?

- What new theories and concepts may explain the intermingling of digitized innovation processes and related innovation outcomes during digital innovation?

- How and under what conditions does an agency become distributed in digital innovation?

- What theories can explain how firms are able to successfully and fluidly mix, match, and integrate internal and external parties and various diverse communities in digital innovation?

- How do digital technologies enable/support problem-solution matching? How do digital technologies enable, constrain, and shape the nature/form of innovation as collective action?

- How do human and material (digital) agencies intermingle in innovation orchestration and to what effect? 
novation can be viewed as a temporary (labile) set of couplings between needs, user affordances, digital artifact features and related sociotechnical "constellations."

A conceptualization of digital innovation as dynamic problem-solution design pairing helps us to fill the gaps created by the challenged assumptions discussed earlier. First, by focusing on problem-solution design pairing, predefined problem solution spaces are replaced with an innovation space of fluid boundaries (one that reflects the flexibility of recombinations afforded by digital technologies). Problem-solution design pairing then helps address a key question: How do digital innovations emerge/form and evolve? Second, problem-solution design pairing also incorporates the potential for innovation agency to be distributedas would-be innovators collaborate in defining and matching problem-solution pairs in multiple contexts. As such, problem-solution pairing helps address a key question: How do firms integrate internal and external parties and various diverse communities in contributing to digital innovation?

Problem-solution pairs can also be imbued with memory, such as memory of earlier couplings. This allows innovation to be simultaneously path dependent and path breaking. For example, a developer can use a Google Maps API to insert a link to a map providing driving directions on a website to solve the problem of navigation. A new developer may take the same app and add new features such as police sightings or construction warnings to address a different problem (of avoiding speed traps). Each evolution incorporates the memory of what has gone before with a new distinct problemsolution pair.

Digital product architectures promote long-lasting and structural differentiation for distinct and separate digital innovations with unique innovation trajectories involving new ways of generating problem-solution pairs (Adomavicius et al. 2008; Lyytinen and Rose 2003). Accordingly, digital innovation can be viewed as a constant search for and identification of new or evolved problem-solution pairs. Such searches may initially focus on replacing existing functions. Over time, these searches may create complements to existing products or services or largely decompose or restructure the current product architecture to several separate layers. As layers are introduced (such as "software stacks"), highly distinct design-solution pairs can be sought to offer new recombination possibilities as well as the potential for open innovation (see Henfridsson et al. 2014; Henfridsson and Yoo 2013; Tilson et al. 2010).

The discovery and matching of problem-solution pairs depends on the richness and plausibility of design patterns that can be mobilized by the innovators. Patterns serve here for innovators as "rules of thumb that provide a plausible aid in structuring a problem at hand or in searching for a satisficing artifact design" (Gregory and Muntermann 2014, p. 639). Similarly, they serve "as a generalized solution to a commonly occurring problem” (Douglass 2003, p. 50). For example, when coding in HTML, the use of a cascading style sheet offers a design pattern. At the business layer, a design pattern can be an exchange transaction, since it is done repeatedly across different systems, assets, or currencies. Generally, design patterns offer tentative relationships between at least two components within a design and a solution that matches with the goals and constraints of the problem.

Such patterns can also serve generally in supporting more distributed innovation agency-one wherein they guide individual innovators in generating problem-solution pairs to match particular contexts. For example, in the case of Volvo (see Svahn et al. 2017), identifying varying design patterns was critical to moving with the creation of an open software platform for the car without knowing completely the desired functionality expected from a connected car. As a result, the company generated a portfolio of platforms, each offering a specific problem-solution pair and where each such pair was grounded on a different and specific design pattern of limited scope and distinct focus.

Accordingly, every digital innovation process can be viewed as a constant discovery, manifestation, and combination of one or more design pattern wherein each pattern identifies a new and different relationship between at least two components of the digital technology functions. The extent of pattern similarity between digital solutions can be potentially used by IS researchers to trace and compare digital innovation processes.

\section{Socio-Cognitive Sensemaking}

The fluidity of the innovation boundaries, the dynamics of matching problem-solution pairs, and the heterogeneity of innovation actors all contribute to shifts in participant cognition and sense making that form a critical element of digital innovation. Here we suggest that a critical element of theorizing about digital innovation management is how digital technologies (artifacts, platforms, etc.) interact with innovation agents (be they organizations or individuals) to foster innovative socio-cognitive sensemaking. By socio-cognitive sensemaking, we mean that the technology is being made sense of simultaneously in an individual innovator's cognition and the innovator's social system of collectives of organizations and individuals. Integrating an understanding of how this socio-cognitive sensemaking influences digital innovation 
processes and outcomes is central to any theory of innovation management.

First consider the need for shared socio-cognitive sensemaking. Digital architectures (layered modular architecture) increase the complexity and comprehensibility of products and services. When an innovation platform spans multiple traditional product categories, the scope of the innovation may be hard to understand by any single innovator and the innovation itself may be given different cognitive frames by different participants; for example, radical digital innovation cognition needs to be extended beyond traditional product and process categories (Lyytinen and Rose 2003; Negro and Leung 2013). If a dominant frame emerges, inertia to reframe may result, inhibiting innovators from perceiving the possibility of new cognitive frames and therefore new innovation opportunities (failure to reframe) (Kaplan and Tripsas 2008; Rosa and Porac 2002). However, when different frames are socially communicated to others so that individuals become motivated to "break" their existing frames, this may allow individuals to see new possibilities with a new cognitive frame, and thus generate new innovation (Verganti 2009). Successful digital innovation thus depends on how actors come to understand, share with others, and then modify their understandings of innovation outcomes, processes, and related markets.

Successful digital innovation, then, calls for relentless deframing and reframing of innovation outcomes and processes, influenced by a social process. This is no different than socio-cognitive innovation with less digital artifacts (Carlile 2004; Harvey 2014; Majchrzak et al. 2012; Tsoukas 2009). However, what is unique with digital artifacts is the ease with which the artifact itself can be modified, and the lack of comprehensibility such that innovation requires an understanding of others' socio-cognitive frames.

Moreover, digital innovation reframing creates a conundrum for the organization. If, on the one hand, radical digital innovation is framed too strongly as an opportunity for new sensemaking, this may be interpreted by the organization as questioning current ways of framing markets and products, leading to an organizational response that is either weak and confusing or rigid and protective (Gregoire et al. 2010). If, on the other hand, the radical digital innovation is framed within current frames, the radical opportunities afforded by the technology may not be understood.

Therefore, an important element of a digital innovation management theory is one that addresses the question of how these socio-cognitive frames about digital innovation are developed and shared. The frames are certainly shaped by narratives of sensemaking interactions between innovating actors (often mediated by digital technologies) and affected by related and past experiences (Garud and Giuliani 2013). Following our notion of problem-solution pairing that evolves and changes over time, innovators (and entrepreneurs) build, share and cocreate narratives around problems and solutions that in turn transform opportunities into new products and services. Such narratives enable "meaning making” (Bruner 1990), that is, innovators "plot sets of social and material elements from the past, present, and future into a comprehensible narrative” (Garud and Giuliani 2013, p. 159). Specifically, narratives "construct realities rather than reduce them through modeling....and as such they grasp the complexities of real life events" (Khan and Sarv 2013, p. 204). The value of such narratives in fostering innovation has been suggested before in the context of communities of practice (e.g., Brown and Duguid 1991) and, more recently, in the broader context of strategic management and entrepreneurship (Müller and Becker 2013; Nambisan and Zahra 2016).

Importantly, digital artifacts may be unique in that they both embody past narratives and portend future narratives (i.e., they inform on the possibilities of the future) (Nambisan 2017). Specifically, the features and functionalities of digital artifacts convey information on the nature of the problemsolution pairs rooted in a specific context. As users discover and use such digital artifacts in newer contexts, they can use digital infrastructures (e.g., social media, crowdsourcing systems) for sharing and cocreating new narratives leading to new digital innovations (Nambisan and Zahra 2016). Indeed, the process of developing an understanding of an emerging innovation opportunity often starts from such narratives as they offer important signals regarding changes in customer aspirations, wants, and demands. As recent studies (e.g., Fischer and Reuber 2011) indicate, interactions on social media enable innovators and entrepreneurs to formulate new opportunities in an incremental and inductive manner. As such, digital innovation can be viewed as a process of social construction (Berger and Luckman 1967) of opportunities from narratives.

Overall, our discussion suggests the potential value of narratives developed through socio-cognitive sensemaking to address two broad sets of questions around digital innovation: First, if innovation agency is distributed, how do innovation agents make sense and discover new meanings around digital technologies and construct related use scenarios and affordances? Second, how do digital technologies facilitate such shared meaning making among a diverse set of innovation agents, thereby fueling future digital innovation?

\section{Technology Affordances and Constraints}

As the distinction between innovation processes and outcomes recede in a digital world and as (digital) tools both 
shape and are shaped by digital products and services, it becomes imperative to develop a deeper understanding of their intermingling. Technology affordances and constraints theory (Gibson 1979; Leonardi 2011; Majchrzak and Markus 2013; Markus and Silver 2008; Treem and Leonardi 2012) offers a promising lens that is particularly well suited to help IS scholars build new theories in this regard.

An affordance (or a constraint) is defined as an action potential offered by the digital technology; it is a relation between a technology with certain features and a users' intent or purpose to which this technology is to be used (Majchrzak and Markus 2013). Thus, the focus is not on what features digital tools or artifacts possess, but how actors' goals and capabilities can be related to the inherent potential offered by the features. By looking at technology use as sets of affordances and constraints for particular innovating actors, IS researchers can explain how and why the same technology can be repurposed by different actors or has different innovation outcomes in different contexts.

Affordances also enable separating digital innovations that emerge during the process of connecting use contexts and features through constant problem-solution matching and innovation within specific features of technologies that are located in specific layers of the architecture stack. This helps deepen and enrich general and substantive theories of digital innovation.

In the digital innovation context, affordances often refer to the way in which innovation process tools are used. For example, in the CRM case outlined in this issue (see Saldanha et al. 2017), the affordance of a relational information process capability for customer engagement was studied and found to increase the probability of eliciting innovations from customers. Other affordances needing to be studied include ways in which customers use new product features, the combinatorial nature of software modules, platforms that facilitate stakeholder collaboration, and flexible modularization for a platform affording changing platform design constraints more quickly. More broadly, how do affordances associate with specific nonfunctional features of digital technology such as the scale and speed of computation, differences in cost and geographical distribution, etc., and how do they, in combination, enable digital innovation? What generic technology affordances are enabled by new digital technologies and how do they influence innovation trajectories and outcomes?

The benefit of the affordance lens is that the specificity of the affordance, which matches the features with the use context, allows specifying more accurate theories which are informed by relationships between affordances, and between affordances and users, between affordances and the needs of inno- vation collectives. For example, how are digital capabilities used in specific innovation contexts and across contexts as specific affordances and how do they shape digital innovation?

Overall, the technology affordance theory helps us to address the challenged assumption regarding the differentiation between innovation process and outcome and, specifically, the important research questions that underlie the emerging complex, dynamic interactions (and duality) between digital innovation processes and outcomes.

\section{Orchestration}

As innovation boundaries get more diffused and innovation agency more distributed, questions related to how digital technologies shape the nature and form of innovation as a collective action gain heightened significance. Here, we suggest the notion of orchestration as a theoretical lens to examine such questions. Prior studies on innovation networks and ecosystems have suggested the concept of orchestration, wherein one or more firms (or entities) assume the responsibility for coordinating value cocreation and value appropriation (e.g., Dhanaraj and Parkhe 2006; Nambisan and Sawhney 2007, 2011; Wind et al. 2009). Building on that, we next discuss aspects of orchestration that are unique to the context of digital technologies and digital innovation.

Previously, we noted how digital innovation could be conceptualized in terms of dynamic problem-solution design pairing. The rise of such dynamic problem-solution pairing has led to the rise of new organizational forms, a form that Afuah and Tucci (2012) call problem-solving organizations. In problem-solving organizations, problems (or needs) and solutions "float around" waiting to be temporarily matched for action potential and capabilities orchestrated within the organization (von Hippel and von Krogh 2016). This model has similarities with the classic "garbage-can" model (Cohen et al. 1972) where the problem and solution pairs came largely from professional capabilities and related organizational stimuli.

Thus, in problem-solving organizations, a loosely connected crowd of "contributors" can be identified and mobilized by a digital technology or person serving - either temporarily or more permanently-to orchestrate the crowd. This orchestration involves waiting for the right problem to enter the stage to match with an available or new potential solution, or helps brokering solutions generated by contributors to plausible problems or opportunities. Thus, in essence, orchestration can be viewed in terms of the matching of problems and needs with potential solutions. Accordingly, here we suggest 
problem-solution matching as a micro-foundation of (digital) innovation orchestration. Such a perspective would allow us to gain a more granular understanding of how innovation occurs when agency is distributed and, more importantly, the role that digital technologies may play in enabling or supporting it.

While prior studies have largely focused on organizational orchestrators (a firm or a group of firms acting as the orchestrator), it is increasingly becoming evident that digital technologies have the potential to match problems (or needs) with solutions and thereby to serve as the orchestrator. Uber can be viewed as an exemplar of this new type of digital orchestration (Libert et al. 2014). Here, Uber drivers are often those with a solution, while passengers are those with a problem, and the Uber algorithm (a digital artifact) does the temporary matching. While Uber (and other such examples) indicate digital orchestration of operations, the increasing sophistication of such (digital) algorithms - for example, deep learning capabilities_-imply their relevance for orchestrating digital innovation.

Digital technologies also play a more indirect and supportive role in innovation orchestration. In digital innovation, problem and solution pairs may emerge from the new functional potential opened by opportunistic and joint sensemaking around digital technologies and the consequent formation of new couplings between needs, affordances, artifacts and the sociotechnical environment. As we noted previously, such joint sense making and problem-solution matching may occur through conversations among a diverse set of actors who own the problems and/or the solutions. By serving as the venue for such conversations, digital platforms (e.g., crowdsourcing and crowdfunding systems) support innovation orchestration. The potential for specific features of such digital platforms to shape those conversations (for example, by supporting actors' search in the problem or solution landscape) imply the need to study the intermingling of human and material (digital) agencies in innovation orchestration. Thus, generally, a focus on orchestration as problem-solution matching opens up important avenues for future research that relates to the design, effectiveness, and boundary conditions of digital technologies as innovation orchestrators.

\section{Innovate in Methods to Study Innovation}

Studying digital innovation management, given the theoretical elements we suggest, may require adopting novel methodologies that have not been used to a great extent in the past. Classic variance based studies are often too static and make too simplistic assumptions about the nature of the phenomenon so the use of such methodologies does not easily get at the heart of the matter. Use of classic qualitative inquiries like the use of small $\mathrm{N}$ case studies or ethnographies helps us reveal and understand the local meanings and related logics, but fails to scale to broader effects of technology and its influence in shaping the context and outcomes of the innovation processes across sites and industries. Something different is called for. Below we note three methodologies that could potentially offer novel insights to the study of digital innovation: computational social science, configurational analysis, and methodologies for identifying complex emergent phenomena.

\section{Computational Social Sciences}

Computational social sciences refers to a set of methodologies for exploring human behavior computationally. These techniques help scale local analysis of the use of digital technologies and innovation around them to broader contexts. At the same time, they seek to remain faithful to the inherent meanings of activities that influence innovation processes and outcomes. The computational sciences cover the use of simulations, data mining, behavioral tracking, or large-scale field experiments. The areas of research on solution-problem pairing and orchestration are particularly well suited to be studied using computational social sciences because much of the pairing and orchestration can be examined with digital traces.

There are many forms of computational social sciences that can be applied to testing and developing new theories of digital innovation management. One form is organizational genetics, in which the digital innovation is decomposed into actors, activities, artifacts, and affordances to identify routines (Gaskin et al. 2014). A study of digital innovation management could use organizational genetics to determine how digital technologies such as digital platforms enable the creation, transformation, and use of new technologies, such as software applications for an automobile or to study innovation processes over time as a set of matching activities and to detect their variation, sources of variation, and outcomes.

Another form of computational social sciences has been referred to as computational case study research (Lindberg 2015). By using sequence analytic approaches, initially made popular by Bakeman and Gottman (1997) and Abbott (2001), this approach seeks to integrate the quantitative big data algorithmic analysis with qualitative narrative development. Digital trace data (which captures human interactions in real time) can be analyzed using computational tools to detect common behavioral patterns over extended periods of time 
subject to qualitative inquiry to interpret the meaning and context of the detected variation in sequences (see, for example, Majchrzak and Malhotra 2017). Digital innovation management could fruitfully employ computational case study research techniques-for example, to generate explanations of how innovation in digital tools changes the way in which engineers or other participating groups do their work.

Another form of computational social sciences has been referred to as process mining (Pentland et al. 2010; van der Aalst 2011). Process mining involves application of Petri nets to elicit processes from event log data. Petri nets are a formalism that allows for formal analysis of concurrency, data-related, and time-related aspects. A process model elicited with Petri nets allows also the modeling of hierarchies between subprocesses, transitions, wait times, and the flow of a token through the work process. As with all business process management models, the elicited processes can be viewed from any of a number of different perspectives, such as organizational unit perspective, resource perspective, roles or actor perspectives, as well as workflow. Process models identified from event logs can be used to compare different models of the work process (Pentland et al. 2010). A study of digital innovation management could use process mining to compare the workflows within innovation projects to discern differences that may explain why one project is more successful than others.

\section{Configurational Analysis}

Identifying problem-solution pairs and technology affordance research creates a need for methodologies that focus on matching specific conditions for specific outcomes rather than variance explanation. One such approach that has begun to receive attention in IS research is qualitative comparative analysis (QCA), and its application to temporal conditions and "fuzzy" conditions (Ragin 2000, 2008). QCA uses Boolean algebraic techniques to compare pair-wise combinations of antecedents and outcome conditions to identify those that produce an outcome. El Sawy et al. (2010) recently argued for the benefits of using QCA in studying configurations of "digital ecodynamics" in information systems research.

\section{Complexity Theory Methods}

Complexity theory has long suggested the central role of bottom-up emergence of self-organization, absent outside direction (McKelvey et al. 2013). Emergence has also been theorized at some length, for example, in the team cognition literature (e.g., Kozlowski and Chao 2012), where it has identified such emergent phenomena as team climate, team goals, and a team's transactive memory. As such, methodologies for identifying emergence can well-apply to the theoretical element of socio-cognitive sensemaking discussed earlier. There are a number of different methodologies that can be used to explore emergence. The most traditional form is the use of agent-based models. For example, Nan's (2011) agent-based simulation model based on Orlikowski’s (1996) case study of social structuration of technology identified the emergence of new work practices as an outgrowth of mutual adaptations between technology and users. Alternatively, the emergence can be identified using behavioral tracing studies as when self-organizing crowds evolve to implicitly coordinate their knowledge sharing to amplify their deliberationresolution capabilities (Kane et al. 2014). Finally, emergence can be identified through field experiments that guide and encourage behavior, but not constrain it. For example, conducting field experiments of different ways of guiding crowds during crowdsourcing led to the emergence of temporarily enacted self-defined roles, in accordance with Faraj et al.'s (2011) theorizing, which led to an increased ability of the crowd to cocreate solutions to problems (Malhotra and Majchrzak 2014).

\section{Articles in this Special Issue}

The six research notes included in the special issue survived a lengthy review process and were selected from an initial pool of 86 full-paper submissions. They offer interesting glimpses to the emerging stream of research on the effects of digitization on innovation processes and outcomes. Here we provide a brief description of each paper and discuss how it relates to the theoretical concepts and research themes discussed above (see Table 2).

The first article, "Embracing Digital Innovation in Incumbent Firms: How Volvo Cars Managed Competing Concerns," is a case study of digital innovation at Volvo Cars. We learn about the paradoxes Volvo experienced while transitioning to the open connected car initiative, which externalizes software development of applications for the vehicle. These paradoxes included balancing between existing and new internal capabilities that needed to be created, balancing between too much product versus too much process innovation, between spending resources to develop internal innovation capabilities versus those of external partners, and between control versus flexible governance over the external development processes. The authors, Fredrik Svahn, Lars Mathiassen, and Rikard Lindgren, illustrate with examples of fascinating ways by which Volvo coped with these paradoxes. Specifically, a series of initiatives to maintain a balance between each side of the paradox were implemented, including a new organiza- 
Table 2. Special Issue Papers

\begin{tabular}{|l|l|}
\hline \multicolumn{1}{|c|}{ Paper Title and Authors } & \multicolumn{1}{c|}{ Key Themes Related to Digital Innovation } \\
\hline $\begin{array}{l}\text { "Embracing Digital Innovation in Incumbent Firms: How } \\
\text { Lars Mathiassen, and Rikard Lindgren }\end{array}$ & $\begin{array}{l}\text { A shift toward more distributed innovation agency raises } \\
\text { key paradoxes with regard to innovation focus, capability } \\
\text { development, resource deployment, and innovation } \\
\text { governance. }\end{array}$ \\
\hline $\begin{array}{l}\text { "Platform Ecosystems: How Developers Invert the Firm," } \\
\text { Geoffrey Parker, Marshall Van Alstyne, and Xiaoyue Jiang }\end{array}$ & $\begin{array}{l}\text { As firms pursue distributed innovations agency through a } \\
\text { platform approach } \\
\text { When does the locus of innovation truly shift? } \\
\text { - how do firms optimize their own intellectual property } \\
\text { regimes in order to maximize growth? }\end{array}$ \\
\hline $\begin{array}{l}\text { "Leveraging Customer Involvement for Fueling Innovation: } \\
\text { Capabilities," Terrence Saldanha, Sunil Mithas, and M. S. } \\
\text { Krishnan }\end{array}$ & $\begin{array}{l}\text { Digital infrastructures (and associated capabilities) com- } \\
\text { plement practices related to distributed innovation agency } \\
\text { to advance innovation. }\end{array}$ \\
\hline $\begin{array}{l}\text { "External Knowledge and Information Technology: } \\
\text { Implications for Process Innovation Performance," } \\
\text { Konstantinos Trantopoulos, Georg von Krogh, Martin Wallin, } \\
\text { and Martin Woerter }\end{array}$ & $\begin{array}{l}\text { Digital infrastructures complement capabilities related to } \\
\text { external knowledge search (and, more broadly, distributed } \\
\text { innovation agency) to advance process innovation. }\end{array}$ \\
\hline $\begin{array}{l}\text { "Growing on Steroids: Rapidly Scaling the User Base } \\
\text { through Digital Innovation," Jimmy Huang, Ola Henfridsson, } \\
\text { Martin Liu, and Sue Newell }\end{array}$ & $\begin{array}{l}\text { Mechanisms that underpin the rapid scaling of user base } \\
\text { by a digital venture (a generative process) imply fluid and } \\
\text { porous innovation boundaries (i.e., associated with existing } \\
\text { services, business models, etc.). }\end{array}$ \\
\hline $\begin{array}{l}\text { "Knowledge Reuse for Customization: Metamodels in an } \\
\text { Open Design Community for 3D Printing," Harris Kyriakou, } \\
\text { Jeffrey Nickerson, and Gaurav Sabnis }\end{array}$ & $\begin{array}{l}\text { Digitization of design knowledge facilitates reuse for cus- } \\
\text { tomization and the factors that shape such reuse imply the } \\
\text { complex interactions between digital innovation processes } \\
\text { and outcomes. }\end{array}$ \\
\hline
\end{tabular}

tional unit called the Connectivity Hub, new design ideology (from a requirements-based to a design-pattern-based approach), separating externally untouchable back-end software from software apps developed by the community, and developing new contracts emphasizing mutual liability and cost neutrality.

The second article, "Platform Ecosystems: How Developers Invert the Firm," addresses key challenges related to the successful and effective distribution of innovation agency on digital platforms. Specifically, Geoffrey Parker, Marshall Van Alstyne, and Xiaoyue Jiang study platform leaders' decisions regarding how much of the core platform they should open (to spur external developer innovation) and for how long they should protect external developers' innovations (before absorbing those innovation into the core platform). Based on an analytical model, the authors show how once a threshold level of external developers is reached, firms would choose to innovate using open external contracts in preference to closed vertical integration, or subcontracts. They also show that while platform-to-platform competition has a linear relationship with such openness, developer-to-developer competition has a non-monotonic effect. Finally, they also show that firms that pursue high-risk innovations with more developers can be more profitable than firms that pursue low risk innovations with fewer developers. More broadly, the study contributes to a deeper understanding of why (and when) external developers might cause a shift in the locus of innovation (i.e., inverting the firm) and how platform firms can optimize their own intellectual property regimes to maximize the growth of digital platforms.

Terrence Saldanha, Sunil Mithas, and M. S. Krishnan in their article, "Leveraging Customer Involvement for Fueling Innovation: The Role of Relational and Analytical Information Processing Capabilities," examine how the complementarities between specific types of customer involvement and specific IT-enabled capabilities enhance firm innovation. Specifically, they suggest that relational information processing capability and analytical information processing capability complement product-focused customer involvement and information-intensive customer involvement practices, 
respectively. Their empirical findings show that firms can benefit more when specific configurations of IT-enabled capabilities are leveraged in unison with specific types of customer involvement. More broadly, their findings suggest new digital infrastructures (and their associated capabilities) can critically complement a firm's practices related to distributed innovation agency (for example, collaboration with customers or a broader ecosystem of external partners) and thus advance firm innovation.

In their paper, "External Knowledge and Information Technology: Implications for Process Innovation Performance," Konstantinos Trantopoulos, Georg von Krogh, Martin Wallin, and Martin Woerter focus on the roles that digital technology plays in compounding the effect of external knowledge search on firms' process innovation. Specifically, using a nine-year panel data from a wide range of Swiss manufacturing firms, they examine how different types of digital infrastructures (data access systems, network connectivity) enhance the impact of deep external knowledge search on firm process innovation. Their findings extend our prior understanding of the complementary role of digital technology to the context of process innovation.

The next paper in this issue, "Growing on Steroids: Rapidly Scaling the User Base through Digital Innovation," focuses on how digital ventures scale their business rapidly by drawing on and adding to digital infrastructure. The authors, Jimmy Huang, Ola Henfridsson, Martin Liu, and Sue Newell, consider such rapid scaling as a generative process that involves reflective actors engaging in digital innovation to increase the user base. Through an in-depth process study of a Chinese digital venture in the credit business, they examine three mechanisms that underlie such a generative process: data-driven operation, instant release, and swift transformation. These mechanisms (and their underlying concepts) hold important implications for future research on digital innovation and speak to some of the themes highlighted here. For example, data driven operation facilitates less bounded innovation; it helps create an abundance of options for future digital innovation that could potentially redefine the boundaries of existing services, business models, etc.

The sixth and final paper in this special issue, "Knowledge Reuse for Customization: Metamodels in an Open Design Community for 3D Printing," examines a fascinating set of issues related to the reuse of digitized design knowledge in a community setting. Specifically, the authors, Harris Kyriakou, Jeffrey Nickerson, and Gaurav Sabnis, use data from Thingiverse, a community of designers that share files for 3D printing, to examine the factors related to reuse for customization (a process in which designers manipulate the parameters of metamodels to produce models that fulfill their personal needs). The study findings illustrate the effects of digitization of design knowledge-via Metamodels — on reuse and the implications for innovation. Broadly, the study speaks to the issues related to the interactions between design processes and outcomes in digital innovation.

\section{Conclusions}

Our objective in this introductory paper has been to lay bare the broader implications of digital innovation for research in innovation management. How should organizations engage in and enhance their innovation outcomes and processes in the digital world? How should we (as students of innovation management) conduct research on the related issues and concepts?

As we noted at the beginning, digital innovation management promises a rich and potentially highly rewarding area of research for information systems researchers. As digital technologies fundamentally transform firms and industries and question the key assumptions and themes that underlie innovation management, research in this area will need to incorporate theoretical concepts and constructs that reflect and capture the myriad ways by which digital material can change both innovation processes and outcomes. As the theoretical logics and conceptual elements that we discussed illustrate, information systems researchers are uniquely positioned to contribute to this emerging research stream.

At the same time, such a discourse on digital innovation management needs to be enjoined by researchers from other disciplines (for example, from computer science, economics, design, sociology, etc.) (Nambisan 2013). Indeed, without such an interdisciplinary effort, it is unlikely that value from the theoretical perspectives identified here would be realized. We hope our discussion here along with the new theoretical concepts and insights offered in the papers included in the special issue will usher in such a broader outlook and help forge a promising path forward in digital innovation management research.

\section{Acknowledgments}

We would like to thank Paulo Goes for giving us the opportunity to work on this special issue. We also gratefully acknowledge valuable comments and suggestions from Arun Rai, Nigel Melville, and the participants of the MISQ Digital Innovation Special Issue Workshop held at the University of Southern California in February 2015. 


\section{References}

Abbott, A. 2001. Time Matters on Theory and Method, Chicago: University of Chicago Press.

Adner, R. 2012. The Wide Lens: A New Strategy for Innovation, London: Penguin UK.

Adomavicius, G., Bockstedt, J. C., Gupta, A., and Kauffman, R. J. 2008. "Making Sense of Technology Trends in the Information Technology Landscape: A Design Science Approach,” MIS Quarterly (32:4), pp. 779-809.

Afuah, A., and Tucci, C. L. 2012. "Crowdsourcing as a Solution to Distant Search,” Academy of Management Review (37:3), pp. 355-375.

Agrawal, A., Horton, J., Lacetera, N., and Lyons, E. 2013. "Digitization and the Contract Labor Market: A Research Agenda," in Economic Analysis of the Digital Economy, A. Goldfarb, S. Greenstein, and C. Tucker (eds.), Chicago: University of Chicago Press, pp. 219-250.

Ahmad, S., Mallick, D. N., and Schroeder, R. G. 2013. “New Product Development: Impact of Project Characteristics and Development Practices on Performance,” Journal of Product Innovation Management (30:2), pp. 331-348.

Anderson, C. L., and Agarwal, R. 2011. "The Digitization of Healthcare: Boundary Risks, Emotion, and Consumer Willingness to Disclose Personal Health Information," Information Systems Research (22:3), pp. 469-490.

Bailey, D. E., Leonardi, P. M., and Barley, S. R. 2012. “The Lure of the Virtual,” Organization Science (23:5), pp. 1485-1504.

Bakeman, R., and Gottman, J. M. 1997. Observing Interaction: An Introduction to Sequential Analysis ( $2^{\text {nd }}$ ed.), Cambridge, UK: Cambridge University Press.

Baldwin, C. Y., and Clark, K. B. 2000. Design Rules: The Power of Modularity (Vol. 1), Cambridge, MA: MIT Press.

Barrett, M., Davidson, E., Prabhu, J., and Vargo, S. L. 2015. "Service Innovation in the Digital Age: Key Contributions and Future Directions,” MIS Quarterly (39:1), pp. 135-154.

Benner, M. J., and Tushman, M. L. 2015. "Reflections on the 2013 Decade Award-'Exploitation, Exploration, and Process Management: The Productivity Dilemma Revisited' Ten Years Later,” Academy of Management Review (40:4), pp. 497-514.

Berger, P. L., and Luckmann, T. 1967. The Social Construction of Reality: A Treatise in the Sociology of Knowledge, Garden City, NY: Anchor Books Doubleday.

Bharadwaj, A., El Sawy, O. A., Pavlou, P. A., and Venkatraman, N. V. 2013. "Digital Business Strategy: Toward a Next Generation of Insights,” MIS Quarterly (37:2), pp. 471-482.

Bogers, M., and West, J. 2012. “Managing Distributed Innovation: Strategic Utilization of Open and User Innovation," Creativity and Innovation Management (21:1), pp. 61-75.

Boland Jr., R. J., Lyytinen, K., and Yoo, Y. 2007. "Wakes of Innovation in Project Networks: The Case of Digital 3-D Representations in Architecture, Engineering, and Construction," Organization Science (18:4), pp. 631-647.

Boudreau, K. 2010. “Open Platform Strategies and Innovation: Granting Access Versus Devolving Control,” Management Science (56:10), pp. 1849-1872.

Boudreau, K. J., and Lakhani, K. R. 2013. "Using the Crowd as an Innovation Partner,” Harvard Business Review (91:4), pp. 60-69.
Bresnahan, T., and Greenstein, S. 2014. "Mobile Computing: The Next Platform Rivalry,” The American Economic Review (104:5), pp. 475-480.

Brown, J. S., and Duguid, P. 1991. “Organizational Learning and Communities-of-Practice: Toward a Unified View of Working, Learning, and Innovation,” Organization Science (2:1), pp. 40-57.

Bruner, J. S. 1990. Acts of Meaning, Cambridge, MA: Harvard University Press.

Carlile, P. R. 2004. “Transferring, Translating, and Transforming: An Integrative Framework for Managing Knowledge Across Boundaries,” Organization Science (15:5), pp. 555-568.

Chandra, Y., and Leenders, M. 2012. "User Innovation and Entrepreneurship in the Virtual World: A Study of Second Life Residents,” Technovation (32:7-8), pp. 464-476.

Chesbrough, H. 2003. Open Innovation: The New Imperative for Creating and Profiting from Technology, Cambridge, MA: Harvard Business School Press Books.

Cohen, M. D., March, J. G., and Olsen, J. P. 1972. “A Garbage Can Model of Organizational Choice,” Administrative Science Quarterly (17:1), pp. 1-25.

Danese, P., and Filippini, R. 2010. "Modularity and the Impact on New Product Development Time Performance: Investigating the Moderating Effects of Supplier Involvement and Interfunctional Integration," International Journal of Operations and Production Management (30:11), pp. 1191-1209.

Dhanaraj, C., and Parkhe, A. 2006. “Orchestrating Innovation Networks,” Academy of Management Review (31:3), pp. 659-669.

Dougherty, D., and Dunne, D. D. 2012. "Digital Science and Knowledge Boundaries in Complex Innovation," Organization Science (23:5), pp. 1467-1484.

Douglass, B. P. 2003. Real-Time Design Patterns: Robust Scalable Architecture for Real-Time Systems (Vol. 1), Upper Saddle River, NJ: Addison-Wesley Professional.

El Sawy, O. A., Malhotra, A., Park, Y, and Pavlou, P. 2010. "Research Commentary: Seeking the Configurations of Digital Ecodynamics: It Takes Three to Tango,” Information Systems Research (21:4), pp. 835-848.

Faraj, S., Jarvenpaa, S. L., and Majchrzak, A. 2011. "Knowledge Collaboration in Online Communities," Organization Science (22:5), pp. 1224-1239.

Fichman, R. G. 2004. “Going Beyond the Dominant Paradigm for Information Technology Innovation Research: Emerging Concepts and Methods," Journal of the Association for Information Systems (5:8), Article 11.

Fischer, E., and Reuber, A. R. 2011. "Social Interaction via New Social Media: (How) Can Interactions on Twitter Affect Effectual Thinking and Behavior?,” Journal of Business Venturing (26:1), pp. 1-18.

Garud, R., and Giuliani, A. 2013. “A Narrative Perspective on Entrepreneurial Opportunities,” Academy of Management Review (38:1), pp. 157-160.

Gaskin, J., Berente, N., Lyytinen, K., and Yoo, Y. 2014. “Toward Generalizable Sociomaterial Inquiry: A Computational Approach for Zooming In and Out of Sociomaterial Routines,” MIS Quarterly (38:3), pp. 849-871.

Gawer, A., and Cusumano, M. A. 2014. "Industry Platforms and Ecosystem Innovation,” Journal of Product Innovation Management (31:3), pp. 417-433. 
Gibson, J. J. 1979. The Ecological Approach to Visual Perception, Boston: Houghton Mifflin.

Goldfarb, A., and Tucker, C. 2012. "Privacy and Innovation,” in Innovation Policy and the Economy (Vol. 12), J. Lerner and S. Stern (eds.), Chicago: University of Chicago Press, pp. 65-89.

Greenstein, S., Lerner, J., and Stern, S. 2013. "Digitization, Innovation, and Copyright: What Is the Agenda?,” Strategic Organization (11:1), pp. 110-121.

Grégoire, D. A., Barr, P. S., and Shepherd, D. A. 2010. “Cognitive Processes of Opportunity Recognition: The Role of Structural Alignment,” Organization Science (21:2), pp. 413-431.

Gregory, R. W., and Muntermann, J. 2014. "Heuristic Theorizing: Proactively Generating Design Theories,” Information Systems Research (25:3), pp. 639-653.

Grönlund, J., Sjödin, D. R., and Frishammar, J. 2010. “Open Innovation and the Stage-Gate Process: A Revised Model for New Product Development," California Management Review (52:3), pp. 106-131.

Hanseth, O., and Lyytinen, K. 2010. "Design Theory for Dynamic Complexity in Information Infrastructures: The Case of Building Internet,” Journal of Information Technology (25:1), pp. 1-19.

Harvey, S. 2014. "Creative Synthesis: Exploring the Process of Extraordinary Group Creativity,” Academy of Management Review (39:3), pp. 324-343.

Henfridsson, O., Mathiassen, L., and Svahn, F. 2014. "Managing Technological Change in the Digital Age: The Role of Architectural Frames,” Journal of Information Technology (29:1), pp. 27-43.

Henfridsson, O., and Yoo, Y. 2013. "The Liminality of Trajectory Shifts in Institutional Entrepreneurship,” Organization Science (25:3), pp. 932-950.

Huang, J., Henfridsson, O., Liu, M., and Newell, S. 2017. "Growing on Steroids: Rapidly Scaling the User Base through Digital Innovation,” MIS Quarterly (41:1), pp. 301-314.

Hui, G. 2014. "How the Internet of Things Changes Business Models,” Harvard Business Review, July 29 (https://hbr.org/ 2014/07/how-the-internet-of-things-changes-business-models; accessed July 29, 2016).

Iansiti, M., and Lakhani, K. R. 2014. "Digital Ubiquity: How Connections, Sensors, and Data Are Revolutionizing Business," Harvard Business Review (92:11), pp. 91-99.

Kallinikos, J., Aaltonen, A., and Marton, A. 2013. "The Ambivalent Ontology of Digital Artifacts,” MIS Quarterly (37:2), pp. 357-370.

Kane, G. C., Johnson, J., and Majchrzak, A. 2014. "Emergent Life Cycle: The Tension Between Knowledge Change and Knowledge Retention in Open Online Coproduction Communities,” Management Science (60:12), pp. 3026-3048.

Kaplan, S., and Tripsas, M. 2008. "Thinking about Technology: Applying a Cognitive Lens to Technical Change,” Research Policy (37:5), pp. 790-805.

Khan, K. U., and Sarv, H. 2013. "From Storytelling to Story Creation by the Use of Systemic Meetings: The Swedish Case," in Narrative and Innovation: New Ideas for Business Administration, Strategic Management and Entrepreneurship, A. P. Müller and L. Becker (eds.), Wiesbaden: Springer, pp. 199-223.

Kozlowski, S. W., and Chao, G. T. 2012. "The Dynamics of Emergence: Cognition and Cohesion in Work Teams," Managerial and Decision Economics (33:5-6) , pp. 335-354.
Kyriakou, H., Nickerson, J., and Sabnis, G. 2017. “Knowledge Reuse for Customization: Metamodels in an Open Design Community for 3D Printing,” MIS Quarterly (41:1), pp. 315-332.

Lakhani, K. R., and Panetta, J. A. 2007. "The Principles of Distributed Innovation,” Innovations (2:3), pp. 97-112.

Langlois, R. N. 2002. "Modularity in Technology and Organization,” Journal of Economic Behavior and Organization (49:1), pp. 19-37.

Lee, J., and Berente, N. 2012. "Digital Innovation and the Division of Innovative Labor: Digital Controls in the Automotive Industry,” Organization Science (23:5), pp. 1428-1447.

Leonardi, P. M. 2011. "When Flexible Routines Meet Flexible Technologies: Affordance, Constraint, and the Imbrication of Human and Material Agencies,” MIS Quarterly (35:1), pp. 147-167.

Libert, B., Wind, Y., and Fenley, M. 2014. "What Airbnb, Uber, and Alibaba Have in Common," Harvard Business Review, November 20 (https://hbr.org/2014/11/what-airbnb-uber-andalibaba-have-in-common; accessed July 29, 2016).

Lindberg, A. 2015. “The Origin, Evolution, and Variation of Routine Structures in Open Source Software Development: Three Mixed Computational--Qualitative Studies,” unpublished Ph.D. Thesis, Case Western Reserve University.

Lusch, R. F., and Nambisan, S. 2015. "Service Innovation: A Service-Dominant Logic Perspective,” MIS Quarterly (39:1), pp. 155-175.

Lyytinen, K., and Rose, G. M. 2003. “The Disruptive Nature of Information Technology Innovations: The Case of Internet Computing in Systems Development Organizations,” MIS Quarterly (27:4), 557-596.

Lyytinen, K., Yoo, Y., and Boland Jr., R. J. 2016. "Digital Product Innovation Within Four Classes of Innovation Networks," Information Systems Journal (26:1), pp. 47-75.

Majchrzak, A., Faraj, S., Kane, G. C., and Azad, B. 2013. “The Contradictory Influence of Social Media Affordances on Online Communal Knowledge Sharing," Journal of Computer-Mediated Communication (19:1), pp. 38-55.

Majchrzak, A., and Malhotra, A. 2017. "Effect of KnowledgeSharing Trajectories on Innovative Outcomes in Temporary Online Crowds," Information Systems Research, forthcoming (DOI: 10.1286/isre.2016.0669).

Majchrzak, A., and Malhotra, A. 2013. “Towards an Information Systems Perspective and Research Agenda on Crowdsourcing for Innovation,” Journal of Strategic Information Systems (22:4), pp. 257-268.

Majchrzak, A., and Markus, M. 2013. "Technology Affordances and Constraints Theory (of MIS)," in Encyclopedia of Management Theory, E. Kessler (ed.), Thousand Oaks, CA: SAGE Publications, pp. 832-836.

Majchrzak, A., More, P. H., and Faraj, S. 2012. "Transcending Knowledge Differences in Cross-Functional Teams,” Organization Science (23:4), pp. 951-970.

Malhotra, A., and Majchrzak, A. 2014. "Managing Crowds in Innovation Challenges,” California Management Review (56:4), pp. 103-123.

Markus, M. L., and Silver, M. S. 2008. “A Foundation for the Study of IT Effects: A New Look at DeSanctis and Poole's Concepts of Structural Features and Spirit," Journal of the Association for Information Systems (9:10/11), pp. 609-632. 
McKelvey, B., Salmador, M. P., Morcillo, P., and Rodríguez-Antón, J. M. 2013. "Towards an Econophysics View of Intellectual Capital Dynamics: From Self-Organized Criticality to the Stochastic Frontier," Knowledge Management Research and Practice (11:2), pp. 142-161.

Müller, A. P., and Becker, L. 2013. Narrative and Innovation: New Ideas for Business Administration, Strategic Management and Entrepreneurship, Wiesbaden: Springer.

Nambisan, S. 2013. "Information Technology and Product/Service Innovation: A Brief Assessment and Some Suggestions for Future Research," Journal of the Association for Information Systems (14:4), pp. 215-226.

Nambisan, S. 2017. "Digital Entrepreneurship: Toward a Digital Technology Perspective of Entrepreneurship,” Entrepreneurship Theory and Practice, forthcoming (DOI: 10.1111/etap.12254).

Nambisan, S., and Sawhney, M. 2007. The Global Brain: Your Roadmap for Innovating Faster and Smarter in a Networked World, Upper Saddle River, NJ: Wharton School Publishing.

Nambisan, S., and Sawhney, M. 2011. "Orchestration Processes in Network-Centric Innovation: Evidence from the Field," Academy of Management Perspectives (25:3), pp. 40-57.

Nambisan, S., and Zahra, S. A. 2016. "The Role of Demand-Side Narratives in Opportunity Formation and Enactment," Journal of Business Venturing Insights (5), pp. 70-75.

Nan, N. 2011. "Capturing Bottom-Up Information Technology Use Processes: A Complex Adaptive Systems Model,” MIS Quarterly (35:2), pp. 505-532.

Negro, G., and Leung, M. D. 2013. ““Actual’ and Perceptual Effects of Category Spanning,” Organization Science (24:3), pp. 684-696.

Nylén, D., and Holmström, J. 2015. "Digital Innovation Strategy: A Framework for Diagnosing and Improving Digital Product and Service Innovation,” Business Horizons (58:1), pp. 57-67.

OECD. 2016. "Stimulating Digital Innovation for Growth and Inclusiveness: The Role of Policies for the Successful Diffusion of ICT,” OECD Digital Economy Papers, No. 256, OECD Publishing, Paris.

Orlikowski, W. J. 1996. “Improvising Organizational Transformation Over Time: A Situated Change Perspective,” Information Systems Research (7:1) 1996, pp. 63-92.

Parker, G., Van Alstyne, M., and Choudary, S. P. 2016. Platform Revolution: How Networked Markets Are Transforming the Economy-And How to Make Them Work for You, New York: W. W. Norton Publishing.

Parker, G., Van Alstyne, M., and Jiang, X. 2017. "Platform Ecosystems: How Developers Invert the Firm,” MIS Quarterly (41:1), pp. 255-266.

Pentland, B. T., Haerem, T., and Hillison, D. 2010. "Comparing Organizational Routines as Recurrent Patterns of Action," Organization Studies (31:7), pp. 917-940.

Porter, M. E., and Heppelmann, J. E. 2014. "How Smart, Connected Products Are Transforming Competition," Harvard Business Review (92:11), pp. 64-88.

Porter, M. E., and Heppelmann, J. E. 2015. "How Smart, Connected Products Are Transforming Companies," Harvard Business Review (93:10), pp. 96-114.

Ragin, C. C. 2000. Fuzzy Set Social Science, Chicago: University of Chicago Press.
Ragin, C. C. 2008. Redesigning Social Inquiry: Fuzzy Set and Beyond, Chicago: University of Chicago Press.

Ries, E. 2011. The Lean Startup: How Today's Entrepreneurs Use Continuous Innovation to Create Radically Successful Businesses, New York: Crown Publishing.

Rosa, J. A., and Porac, J. F. 2002. "Categorization Bases and Their Influence on Product Category Knowledge Structures," Psychology and Marketing (19:6), pp. 503-531.

Saldanha, T., Mithas, S., and Krishnan, M. S. 2017. "Leveraging Customer Involvement for Fueling Innovation: The Role of Relational and Analytical Information Processing Capabilities,” MIS Quarterly (41:1), pp. 267-286.

Sanchez, R., and Mahoney, J. T. 1996. "Modularity, Flexibility, and Knowledge Management in Product and Organization Design,” Strategic Management Journal (17:S2), pp. 63-76.

Sawhney, M., and Prandelli, E. 2000. "Communities of Creation: Managing Distributed Innovation in Turbulent Markets,” California Management Review (42:4), pp. 24-54.

Schilling, M. A. 2000. "Toward a General Modular Systems Theory and its Application to Interfirm Product Modularity,” Academy of Management Review (25:2), pp. 312-334.

Sivasubramaniam, N., Liebowitz, S. J., and Lackman, C. L. 2012. "Determinants of New Product Development Team Performance: A Meta Analytic Review,” Journal of Product Innovation Management (29:5), pp. 803-820.

Smith, A., Sabine, H., Sascha, D., Johan, S., and van Oost, E. 2013. "Grassroots Digital Fabrication and Makerspaces: Reconfiguring, Relocating and Recalibrating Innovation?,” SPRU Working Paper, University of Sussex, Brighton, Sussex.

Staudenmayer, N., Tripsas, M., and Tucci, C. L. 2005. "Interfirm Modularity and its Implications for Product Development," Journal of Product Innovation Management (22:4), pp. 303-321.

Svahn, F., Mathiassen, L., and Lindgren, R. 2017. "Embracing Digital Innovation in Incumbent Firms: How Volvo Cars Managed Competing Concerns,” MIS Quarterly (41:1), pp. 239-253.

Swanson, E. B. 1994. "Information Systems Innovation among Organizations,” Management Science (40:9), pp. 1069-1092.

Tilson, D., Lyytinen, K., and Sørensen, C. 2010. “Digital Infrastructures: The Missing IS Research Agenda,” Information Systems Research (21:4), pp. 748-759.

Tiwana, A., Konsynski, B., and Bush, A. A. 2010. "Platform Evolution: Coevolution of Platform Architecture, Governance, and Environmental Dynamics,” Information Systems Research (21:4), pp. 675- 687.

Treem, J. W., and Leonardi, P. M. 2012. "Social Media Use in Organizations: Exploring the Affordances of Visibility, Editability, Persistence, and Association," Communication Yearbook (36), pp. 143-189.

Trantopoulos, K., von Krogh, G., Wallin, M., and Woerter, M. 2017. "External Knowledge and Information Technology: Implications for Process Innovation Performance," MIS Quarterly (41:1), pp. 287-300.

Tsoukas, H. 2009. "A Dialogical Approach to the Creation of New Knowledge in Organizations,” Organization Science (20:6), pp. 941-957.

Ulrich, K. T., and Eppinger, S. D. 2011. Product Design and Development (5 ${ }^{\text {th }}$ ed.), New York: McGraw-Hill Education. 
Van Der Aalst, W. 2011. Process Mining: Discovery, Conformance and Enhancement of Business Processes, Heidelberg: Springer.

Verganti, R. 2009. Design Driven Innovation: Changing the Rules of Competition by Radically Innovating What Things Mean, Boston: Harvard Business Press.

von Hippel, E., and von Krogh, G. 2016. "Identifying Viable 'Need-Solution Pairs': Problem Solving Without Problem Formulation,” Organization Science (27:1), pp. 207-221.

Wind, Y. J., Fung, V., and Fung, W. 2009. "Network Orchestration: Creating and Managing Global Supply Chains Without Owning Them,” in The Network Challenge: Strategy, Profit, and Risk in an Interlinked World, P. R. Kleindorfer, and Y. Wind (eds.), Upper Saddle River, NJ: FT Press, pp. 299-315.
Xue, L., Zhang, C., Ling, H., and Zhao, X. 2013. "Risk Mitigation in Supply Chain Digitization: System Modularity and Information Technology Governance," Journal of Management Information Systems (30:1), pp. 325-352.

Yoo, Y., Boland Jr., R. J., Lyytinen, K., and Majchrzak, A. 2012. Organizing for Innovation in the Digitized World,” Organization Science (23:5), pp. 1398-1408.

Yoo, Y., Henfridsson, O., and Lyytinen, K. 2010. “The New Organizing Logic of Digital Innovation: An Agenda for Information Systems Research,” Information Systems Research (21:4), pp. 724-735.

Zittrain, J. 2008. The Future of the Internet and How to Stop It, New Haven, CT: Yale University Press. 